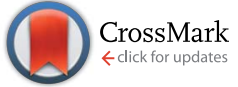

Cite this: RSC Adv., 2017, 7, 8467

\title{
Effect of molten carbonate composition on the generation of carbon material
}

\author{
Hongjun $\mathrm{Wu}{ }^{\mathrm{a}}$ Zhida Li, ${ }^{a}$ Deqiang $\mathrm{Ji}^{a}{ }^{a}$ Yue Liu, ${ }^{a}$ Guanlin $\mathrm{Yi}{ }^{\mathrm{a}}$ Dandan Yuan, ${ }^{a}$ \\ Baohui Wang ${ }^{\star a}$ and Zhonghai Zhang ${ }^{\star b}$
}

Carbon dioxide, $\mathrm{CO}_{2}$, is thought to be a main culprit leading to global climate change and a wide variety of strategies have been proposed to reduce atmospheric $\mathrm{CO}_{2}$ levels. Here, $\mathrm{CO}_{2}$ is captured and subsequently electrochemically split into carbon materials in an electrolyzer comprising a eutectic mixture of carbonates, an Fe cathode and a Ni anode, at $600^{\circ} \mathrm{C}$ and current densities of 50, 100, $200 \mathrm{~mA} \mathrm{~cm}^{-2}$. SEM, EDS, XRD and BET are employed to analyze the morphology, elemental composition, crystal structure as well as the BET surface area of the synthetic cathodic products. In addition, coulomb efficiency under different electrolytic conditions is measured via the comparison between moles of formed carbon product and the Faradays of charge passed during the electrolysis reaction. This paper investigated the effect of molten carbonate compositions on carbon product generation, and confirmed the visible dependence of produced carbon on the electrolytes.

Received 14th October 2016 Accepted 9th January 2017

DOI: 10.1039/c6ra25229j

www.rsc.org/advances

\section{Introduction}

The increased carbon dioxide $\left(\mathrm{CO}_{2}\right)$ emission that stems from human over-reliance on limited fossil fuels as the principal energy source has been cited as a major contributor to the greenhouse effect and global warming: ${ }^{1-4}$ The shocking growth rate of $\mathrm{CO}_{2}$ emission in turn has motivated researchers all over the world to seek feasible methods to effectively control the vast generation of $\mathrm{CO}_{2}$. Currently, the technology of carbon capture and storage (CCS) involving chemisorption ${ }^{5,6}$ and physisorption ${ }^{7-10}$ is being considered and developed, but objections also exist for its costly venture. ${ }^{11}$ Note, that $\mathrm{CO}_{2}$ is not only a greenhouse gas needed to be captured and stored, but an ideal C1 feedstock that can be applied in the field of synthesizing carbonaceous products. ${ }^{12,13}$ Therefore, the preparation of value-added, carbonaceous chemicals from $\mathrm{CO}_{2}$ emitted by industry is both an economic and environmental-friendly option that could alleviate the pressure of environmental degradation and the energy crisis simultaneously.

In recent years, researches on $\mathrm{CO}_{2}$ capture and conversion via electrolysis in molten salts have made great progress, where appropriate electrode materials, electrolyte, and reaction conditions are demonstrated to be of vital significance. ${ }^{\mathbf{1 4}}$ Molten salts, and in particular molten carbonates, used as the electrolyte for this electrochemical conversion is due to their natural properties, including excellent heat and ion conduction, fast reaction kinetics as well as a wide electrochemical window, etc. ${ }^{15,16}$ With the aid of

${ }^{a}$ Provincial Key Laboratory of Oil \& Gas Chemical Technology, College of Chemistry \& Chemical Engineering, Northeast Petroleum University, Daqing, 163318, China. E-mail:wangbh@nepu.edu.cn

${ }^{b}$ Department of Chemistry, East China Normal University, 500 Dongchuan Road, Shanghai,200241, China.E-mail: zhzhang@chem.ecnu.edu.cn eutectic salts electrolyte, $\mathrm{CO}_{2}$ can be captured and subsequently converted into carbon monoxide (CO) ${ }^{17}$ solid carbon ${ }^{18,19}$ and even valuable chemicals of carbon nanofibers (CNFs) or their hollow form of carbon nanotubes (CNTs) ${ }^{20,21}$ that are widely applied in the manufacture of reinforced composites due to outstanding mechanical properties. Presently, carbonates, especially alkali carbonates of $\mathrm{Li}_{2} \mathrm{CO}_{3}, \mathrm{Na}_{2} \mathrm{CO}_{3}$ and $\mathrm{K}_{2} \mathrm{CO}_{3}$, are widely recognised as the optimum choice for $\mathrm{CO}_{2}$ capture and conversion, but to the best of our knowledge, rare work is dedicated to investigate the effect of carbonates composition on carbon production. In this work, $\mathrm{Li}_{2} \mathrm{CO}_{3}, \mathrm{Na}_{2} \mathrm{CO}_{3}$ and $\mathrm{K}_{2} \mathrm{CO}_{3}$ are mixed to form a binary or ternary molten carbonates electrolyte system to serve as an efficient site for electroreduction of $\mathrm{CO}_{2}$ into carbon powder; a $10 \mathrm{~cm}^{2}$ Fe wire and a $10 \mathrm{~cm}^{2} \mathrm{Ni}$ wire are employed as cathode and anode, respectively. This paper highlights the effect of electrolytes with diverse alkali carbonates composition on the morphology and structure of the carbon product. Besides, charge and energy consumption at different electrolytes is also measured to see whether this electrochemical conversion can proceed at a relatively high coulomb efficiency.

\section{Experimental}

\subsection{Methods and materials}

An electrolysis system comprising a Fe cathode $\left(10 \mathrm{~cm}^{2}\right)$, a $\mathrm{Ni}$ anode $\left(10 \mathrm{~cm}^{2}\right)$, and a corundum crucible $\left(\mathrm{Al}_{2} \mathrm{O}_{3}\right.$, purity $\left.>99 \%\right)$ used to contain alkali carbonates $\left(\mathrm{Li}_{2} \mathrm{CO}_{3}, \mathrm{Na}_{2} \mathrm{CO}_{3}\right.$ and $\left.\mathrm{K}_{2} \mathrm{CO}_{3}\right)$ with diverse mass ratio is established to allow the continuous adsorption and electrochemical conversion of $\mathrm{CO}_{2}$ into solid carbon. The electrodes of $\mathrm{Fe}$ and Ni are purchased from Hebei steady metal products co., LTD and need to be polished and 


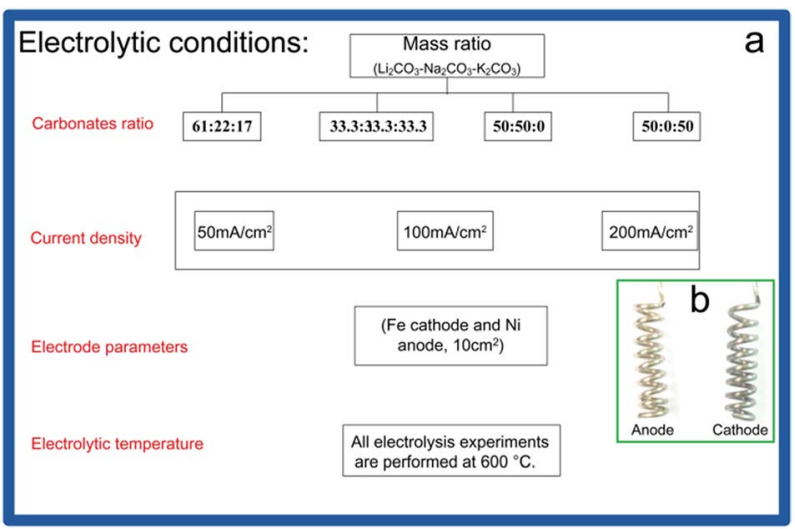

Fig. 1 (a) Specific experimental conditions and (b) electrodes before electrolysis.

stored in oil before electrolysis to avoid the surface oxidation. $\mathrm{Li}_{2} \mathrm{CO}_{3}, \mathrm{Na}_{2} \mathrm{CO}_{3}$ and $\mathrm{K}_{2} \mathrm{CO}_{3}$ are all of analytical purity, provided by Tianjin BA Chemical Reagent Factory.

The corundum crucible filled with mixed carbonates is set on a ceramic heating jacket heated by electricity. Before electrolysis, temperature of the corundum crucible is kept at $>700{ }^{\circ} \mathrm{C}$ for several hours to ensure that the mixed carbonates can reach to molten state and moisture of the carbonates is removed. Then the temperature is cooled down to presupposed electrolytic temperature of $600{ }^{\circ} \mathrm{C}$ for electrolysis. The experiments are carried out at current densities of $50 \mathrm{~mA} \mathrm{~cm}^{-2}, 100 \mathrm{~mA} \mathrm{~cm}{ }^{-2}, 200$ $\mathrm{mA} \mathrm{cm}{ }^{-2}$ for $2 \mathrm{~h}, 1 \mathrm{~h}$ and $0.5 \mathrm{~h}$, respectively, and then, cathode covered with carbon product is pulled out from the molten salts and carefully uncoiled. The extracted carbon product is subsequently subject to a series of post-electrolysis treatments, including acid picking $(\mathrm{HCl})$, ultraphonic (10 $\mathrm{min})$, bath heating $\left(60{ }^{\circ} \mathrm{C}\right)$, suction filtration $(0.4 \mu \mathrm{m}$ filter membrane), abstersion (deionized water) and desiccation $\left(80^{\circ} \mathrm{C}, 6 \mathrm{~h}\right)$. Except experiment for $\mathrm{GC}$ analysis conducted at Ar atmosphere (to avoid effect of air components on the analysis of gaseous product), other experiments are performed at air atmosphere. Fig. 1a depicts the experimental conditions in detail. Pictures of helical electrodes (Ni anode, Fe cathode) before electrolysis are shown in Fig. 1b.

\subsection{Characterization}

Elemental composition of purified cathodic product is studied by Energy Dispersive Spectroscope (EDS, X-Max, the British Oxford Instruments co., LTD). Micromorphologies and microstructures of the carbon sample are studied by Scanning Electron Microscope (SEM, SIGMA, Zeiss company) at working voltage of $10 \mathrm{kV}$, X-ray diffraction (XRD, step of 0.02, X-ray of $40 \mathrm{kV} / 40 \mathrm{~mA}, \mathrm{D} / \mathrm{MAX}$ 2200) as well as Brunauer-Emmett-Teller analysis (BET, Tristar3020, Micromeritics Instrument Corporation).

\section{Results and discussion}

\subsection{Reaction mechanism}

$\mathrm{CO}_{2}$ removal proceeds via the electrolytic transformation of tetravalent carbon in proximity to the Fe cathode into solid and zerovalent carbon. Electrochemical reduction of $\mathrm{CO}_{2}$ into solid carbon in molten carbonates is generally thought to occur in 3 different reaction mechanisms, ${ }^{14}$ which are corresponding to eqn (1)-(3), respectively. However, it seems that more authors tend to approve the theory that $\mathrm{CO}_{2}$ is degraded into elemental carbon via the reduction of $\mathrm{CO}_{3}{ }^{2-}$ in molten melts (eqn (1)). Expounded by this mechanism, $\mathrm{CO}_{3}{ }^{2-}$ ions are directly reduced into solid carbon (lower electrolytic temperature, $T<\sim 850^{\circ} \mathrm{C}$ ) or CO (higher electrolytic temperature, $T>\sim 850{ }^{\circ} \mathrm{C}$ ) and $\mathrm{O}^{2-}$ during the electrolysis reaction, and the produced $\mathrm{O}^{2-}$ ions besides being oxidized into oxygen (eqn (5)) as a by-product, further act as an absorbent for atmospheric $\mathrm{CO}_{2}$ (eqn (4)), allowing the regeneration of molten carbonates electrolyte. ${ }^{21}$ Thus, a perfect circulation of $\mathrm{CO}_{2} \rightarrow \mathrm{C} / \mathrm{CO}+\mathrm{O}_{2}$ is formed, wherein electricity consumed by this process can be replaced by sustainable energy, including solar power, wind energy, tidal energy, etc. Scheme 1 illustrates the carbon formation mechanism set forth by eqn (1), (4), and (5). Note, electrochemical conversion from $\mathrm{CO}_{2}$ to solid carbon in such molten carbonates sites is quite a complicated process, and eqn (1), (4), (5) are merely a simplification of the overall reaction, with many other complex electrochemical reactions proceeding at the same time.

$$
\begin{aligned}
\mathrm{CO}_{3}{ }^{2-}+4 \mathrm{e}^{-} & \rightarrow \mathrm{C}+3 \mathrm{O}^{2-} \\
\mathrm{CO}_{2}{ }^{2-}+2 \mathrm{e}^{-} & \rightarrow \mathrm{C}+2 \mathrm{O}^{2-} \\
4 \mathrm{M}+\mathrm{M}_{2} \mathrm{CO}_{3} & \rightarrow \mathrm{C}+3 \mathrm{M}_{2} \mathrm{O} \\
\mathrm{CO}_{2}+\mathrm{O}^{2-} & \rightarrow \mathrm{CO}_{3}^{2-} \\
\mathrm{O}^{2-}-4 \mathrm{e}^{-} & \rightarrow \mathrm{O}_{2}
\end{aligned}
$$

It has been addressed that electroreduction of $\mathrm{CO}_{3}{ }^{2-}$ ions into solid carbon merely occurs at electrolyte containing lithium and carbonate $\left(\mathrm{Li}^{+}, \mathrm{CO}_{3}{ }^{2-}\right)$, and therefore, no carbon powder is deposited in eutectic electrolyte of Na-K (Li-free) carbonates. ${ }^{14}$ The required electrolytic potential as a function of temperature calculated from relevant thermodynamic data (taken from website of NIST) can be invoked to explain why $\mathrm{Li}_{2} \mathrm{CO}_{3}$ reduction

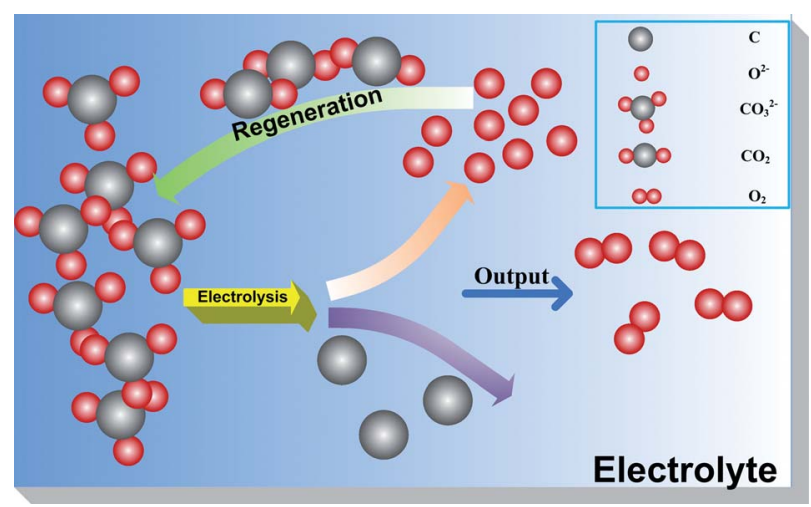

Scheme 1 Indirect conversion of $\mathrm{CO}_{2}$ into solid carbon at cathode and regeneration of the carbonate eutectic. 
to carbon is more favorable than $\mathrm{Na}_{2} \mathrm{CO}_{3}$ and $\mathrm{K}_{2} \mathrm{CO}_{3}$. Relative to $\mathrm{Na}_{2} \mathrm{CO}_{3}$ and $\mathrm{K}_{2} \mathrm{CO}_{3}$, potential required by $\mathrm{Li}_{2} \mathrm{CO}_{3}$ to generate carbon is more positive than that to form Li metal via reduction of $\mathrm{Li}^{+}$ions, evincing a preference for carbon deposition. As for eutectic of $\mathrm{Na}_{2} \mathrm{CO}_{3}$ and $\mathrm{K}_{2} \mathrm{CO}_{3}$, potential of carbon generation is comparative or even more negative than that of metal production, resulting in no carbon product and instead alkali metal is the preferred reduction product. However, a carbon product is observed from each of the following two Li-free molten carbonate electrolytes: a binary $\mathrm{Na}_{2} \mathrm{CO}_{3} / \mathrm{BaCO}_{3}$ mix or a ternary $\mathrm{Na}_{2} \mathrm{CO}_{3} / \mathrm{K}_{2} \mathrm{CO}_{3} / \mathrm{CaCO}_{3}$ mix electrolyte. ${ }^{22}$

In an electrolyte of $\mathrm{Li}-\mathrm{Na}-\mathrm{K}$ carbonates mixed by 33.3 : $33.3: 33.3$ wt $\%\left(600{ }^{\circ} \mathrm{C}, 100 \mathrm{~mA} \mathrm{~cm}{ }^{-2}\right.$, a $10 \mathrm{~cm}^{2} \mathrm{Fe}$ cathode, a $10 \mathrm{~cm}^{2} \mathrm{Ni}$ anode), the obtained carbon product comprises five elements (Fig. 2a): C (93\%), O (5\%), Na (0.7\%), K $(1.1 \%), \mathrm{Au}(0.2 \%)$, and all content is mole ratio. It should be noted that the peak of $\mathrm{Au}$ is from coating for SEM characterization. We can see that $\mathrm{C}$ occupies an overwhelmingly larger mole fraction (93\%) in comparison to that of $\mathrm{O}$, only $\sim 5 \%$, denoting that the cathodic product is likely to be elemental carbon with bits of oxygen-containing functional groups. ${ }^{23}$ The presence of alkali metals, $\mathrm{Na}$ and $\mathrm{K}$, in cathodic product verifies that carbon deposition is accompanied by very little codeposition of alkali metals, which serves as an enabler for the decrease in coulomb efficiency. Additionally, small amounts of CO generation is also confirmed by gas chromatography (GC, Agilent 7890B) equipped with thermal conductivity detector (TCD), displayed in Fig. 2b. In this process, reaction is carried out at a sealed steel reactor, Ar atmosphere, and a vacuum pump

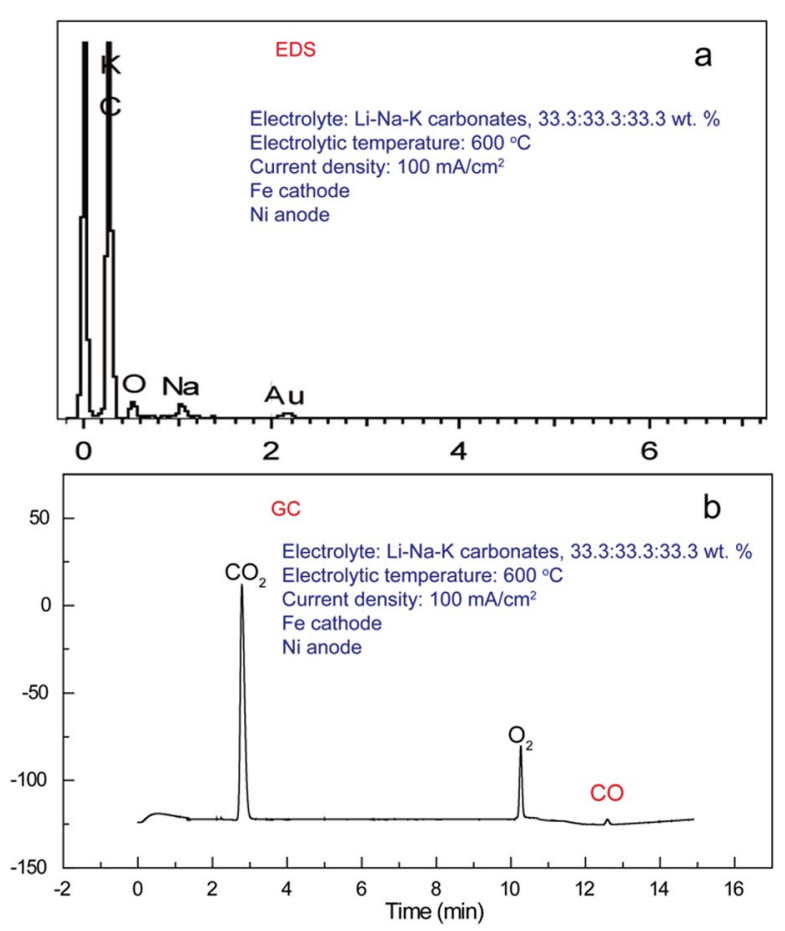

Fig. 2 (a) EDS of the solid product and (b) GC analysis of the gas product, obtained from $\mathrm{Li}-\mathrm{Na}-\mathrm{K}$ (33.3:33.3: 33.3 wt\%), $100 \mathrm{~mA} \mathrm{~cm}^{-2}, 600^{\circ} \mathrm{C}$. is utilized to collect gas product every 15 minutes to avoid produced gas atmosphere inside the reactor. TCD signal displays distinctive, separated $\mathrm{CO}_{2}, \mathrm{O}_{2}$, and $\mathrm{CO}$ peaks at retention time of $2.786,10.263,12.585 \mathrm{~min}$ respectively, indicating the formation of $\mathrm{CO}_{2}$ (thermal decomposition of carbonate, such as $\mathrm{Li}_{2} \mathrm{CO}_{3} \rightarrow$ $\mathrm{Li}_{2} \mathrm{O}+\mathrm{CO}_{2}$ ), $\mathrm{O}_{2}$ (anodic product), and $\mathrm{CO}$ (cathodic by-product). No other peaks are observed at GC results, implying that there is no other composition in the gaseous product. Under ambient molten conditions the carbonate electrolyte is stable. However (in addition to $\mathrm{O}_{2}$ product), the vacuum removal of the gas favors the low pressures decomposition of the molten electrolyte as: carbonate (molten) $\rightarrow$ oxide (dissolved) $+\mathrm{CO}_{2}$ (gas). Different from co-electrolysis of $\mathrm{CO}_{2}$ and $\mathrm{H}_{2} \mathrm{O}$ system, ${ }^{24}$ no methane is detected due to the lack of hydrogen source. The low, but important formation of $\mathrm{CO}$ demonstrates that $\mathrm{CO}_{2}$ splitting into zerovalent carbon isn't the exclusive degradation pathway at temperature of $T<\sim 850{ }^{\circ} \mathrm{C}$, accompanied by very little $\mathrm{CO}$ generation that is presumably to occur at $T>\sim 850^{\circ} \mathrm{C}$.

\subsection{Micromorphology and microstructure characterization}

SEM images of the carbon product prepared in diverse alkali carbonates are given at Fig. 3 that exhibits a dramatic morphological evolution. It has been proved that the microscopic morphology and structure of the deposited carbon product are remarkably affected by the composition of the mixed molten carbonates, ${ }^{21}$ and here, this dependence is verified again. Carbon product obtained from a binary mixture of carbonates ( $\mathrm{Li}-\mathrm{Na}, 50: 50 \mathrm{wt} \%$ ) possesses a very interesting microstructure that is formed by an accumulation of carbon spherical particles with a wide diameter distribution. Observed from SEM image (Fig. 3a), diameters of these spherical particles range from tens of nanometers to a few micrometers, which maybe dependent on electrolytic temperature as well as applied cell voltage/current density. However, in a system of Li-K binary carbonates mixed by $50: 50$ (wt\%), the electro-deposited carbon present a noticeably different morphology of nanoflakes with thickness ranging from 50-200 $\mathrm{nm}$ (Fig. 3b) rather than a spherical structure from Li-Na system. Further morphological

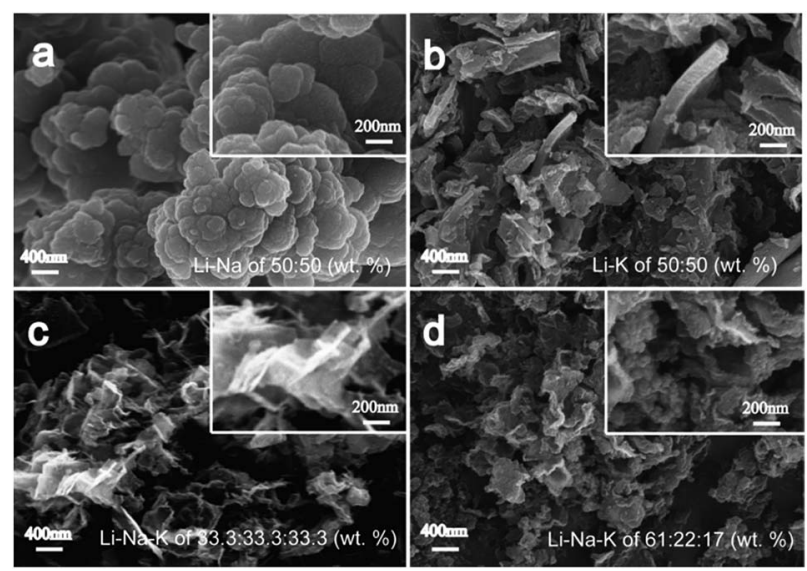

Fig. 3 SEM of carbon product prepared at $100 \mathrm{~mA} \mathrm{~cm}^{-2}, 600{ }^{\circ} \mathrm{C}$ and diverse electrolytes. 
changes occur at a ternary electrolyte of $\mathrm{Li}-\mathrm{Na}-\mathrm{K}$ carbonates. Micromorphology of the carbon product obtained at electrolyte of $33.3: 33.3: 33.3$ (wt $\%$ ) presents a nanoflake-like structure with sharp edges (Fig. 3c). As composition of the molten carbonates electrolyte ( $\mathrm{Li}-\mathrm{Na}-\mathrm{K}$ ) is according to $61: 22: 17$ (wt\%), analogous morphology (shown in Fig. 3d) to that prepared in electrolyte of $33.3: 33.3: 33.3$ (wt\%) is observed rather than a mixture of nanoparticles and nanotubular structure prepared at $\sim 600{ }^{\circ} \mathrm{C}$ with $\mathrm{Fe}$ as cathode and $\mathrm{Ni}-\mathrm{Cr}$ alloy as anode ${ }^{21}$ indicating that electrode material is also one of the influential factors on morphology of the deposited carbon product. Corrosion resistance and conductive ability of anode material could indirectly change the voltage on electrolysis system, resulting in different deposition rate and various microstructure formations sequentially. Minor difference between the synthesized carbon product at $33.3: 33.3: 33.3$ (wt\%) and $61: 22: 17$ (wt\%) alkali carbonates is that a curly flake-like micromorphology with rough surface is formed at $61: 22: 17$ (wt\%), while a thinner and more smooth-surfaced flake-like structure is deposited at $33.3: 33.3: 33.3$ (wt\%).

We have previously noted the noteworthy increase in BET surface area at elevated current density, ${ }^{21}$ and in this work, this finding is proved again. As an example, the BET surface area of carbon product prepared at $\mathrm{Li}-\mathrm{Na}$ carbonates of $50: 50 \mathrm{wt} \%$ increases to $80.3 \mathrm{~m}^{2} \mathrm{~g}^{-1}$ at $200 \mathrm{~mA} \mathrm{~cm}{ }^{-2}$, nearly twice over of that at $50 \mathrm{~mA} \mathrm{~cm} \mathrm{~cm}^{-2}\left(39.9 \mathrm{~m}^{2} \mathrm{~g}^{-1}\right)$. This proven increase could be attributed to that larger applied current density facilitates formation of incompact structure, and in this manner, carbon product with higher BET surface area deposits at cathode. Moreover, through the comparison and evaluation among these 4 electrolyte systems, it can be found that $\mathrm{Li}-\mathrm{Na}$ carbonates system favours generation of carbon product with smaller particle size and higher BET surface area, reflected on the primary micromorphology of carbon spheres, rather than irregular carbon flakes and amorphous carbon. Another, as far as we know, BET surface area of as-prepared carbon is also significantly dependent on electrolytic temperature, that is, lower temperature prefers carbon deposition with higher BET surface area. Taking Tang's work as a supporting example, BET surface area increases from $101.89 \mathrm{~m}^{2} \mathrm{~g}^{-1}$ of $650{ }^{\circ} \mathrm{C}$ to $212.39 \mathrm{~m}^{2} \mathrm{~g}^{-1}$ of $550{ }^{\circ} \mathrm{C}$ at the same voltage, and this conspicuous increase is likely due to the slower deposition rate at lower applied temperature. ${ }^{23}$ Carbon electrodeposition in molten salts electrolyte is constrained by electrons arriving from the cathode at the electrolyte interface and thus, microstructure is significantly affected by electrolytic parameters, including molten salts composition, applied current density, electrolytic temperature, etc. (Table 1).

As seen from Fig. 4a-d, massive spherical carbon particles with diverse diameters (micron grade) stack together irregularly. Formation of these deposited carbon sphere aggregates is likely owing to the nucleating effect of the initially generated carbon powder in this electrolyte environment, acting as a substrate for further carbon deposition. Presently, due to the potential utilizations as reinforcement materials or matrix for rubber, catalyst supports, lubricating materials, anodes in second Li-ion batteries, hydrogen storage media, etc., carbon spheres as a new reinforcement agent have drawn extensive
Table 1 BET surface area of the carbon sample prepared at diverse electrolytic conditions

\begin{tabular}{lrl}
\hline Electrolyte composition $(\mathrm{wt} \%)$ & $\begin{array}{l}\text { Current density } \\
\left(\mathrm{mA} \mathrm{cm}^{-2}\right)\end{array}$ & $\begin{array}{l}\text { BET surface } \\
\text { area }\left(\mathrm{m}^{2} \mathrm{~g}^{-1}\right)\end{array}$ \\
\hline Li-Na of $50: 50$ & 50 & 39.9 \\
& 100 & 44.9 \\
& 200 & 80.3 \\
Li-K of $50: 50$ & 50 & 14.5 \\
& 100 & 19.5 \\
Li-Na-K of $33.3: 33.3: 33.3$ & 200 & 47.2 \\
& 50 & 34.5 \\
& 100 & 46.5 \\
Li-Na-K of $61: 22: 17$ & 200 & 69.1 \\
& 50 & 13.2 \\
& 100 & 25.7 \\
& 200 & 59.6 \\
\hline
\end{tabular}

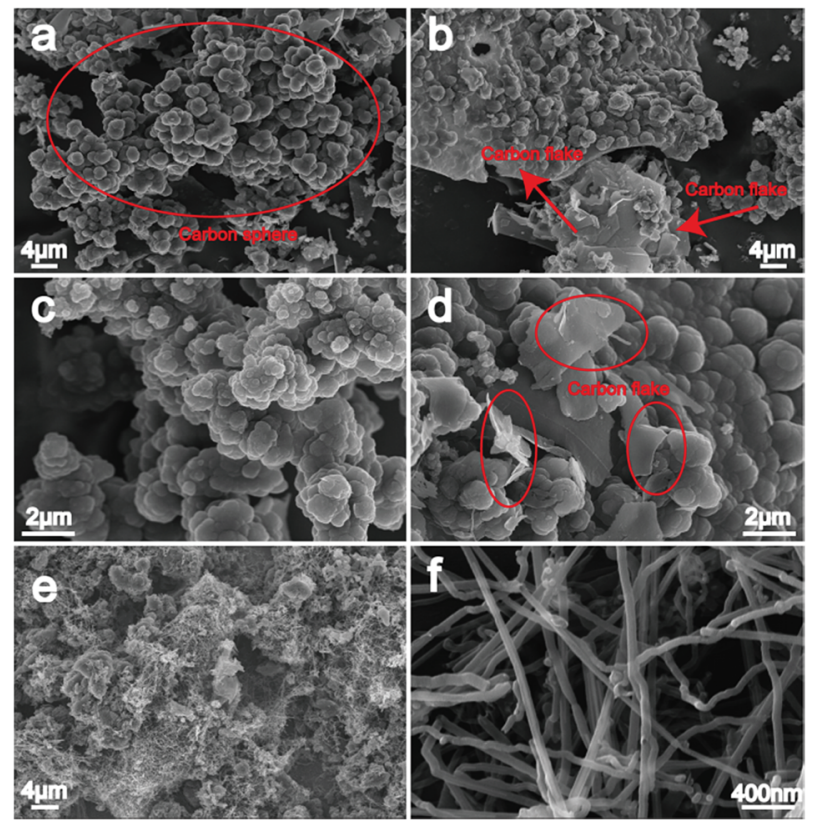

Fig. 4 (a) - (d) are lower magnification SEM images of carbon spheres obtained at $\mathrm{Li}-\mathrm{Na}(50: 50 \mathrm{wt} \%), 600^{\circ} \mathrm{C}$; (e) and (f) are carbon product synthesized at $\mathrm{Li}-\mathrm{Na}(50: 50 \mathrm{wt} \%), 750{ }^{\circ} \mathrm{C}$.

attention and interests from carbon scientists worldwide. ${ }^{25-30}$ Especially, for some sophisticated applications, monodisperse and smooth-surfaced carbon spheres are shown to be required and advantageous. ${ }^{31,32}$ Particle size, structure as well as surface chemistry are demonstrated to be three vital influencing factors on their practical properties. ${ }^{33}$ Therefore, particular attention will be focused on the dispersion and characterization of the above carbon spheres to realize their valuable application on industry. In addition to carbon spheres, flake-like morphology is observed in carbon samples as well (red mark in Fig. 4b and d), growing under/mixed with carbon spheres. Throughout the previous reports, flake-like electrodeposited carbon samples are shown to be a common micromorphology, ${ }^{21,23}$ whose thickness is also visibly affected by electrolytic temperature and applied cell voltage/current density. 
Li-Na mixed carbonates are considered to be an efficient, economic, stable electrolyte for $\mathrm{CO}_{2}$ capture and electrochemical conversion as it can simultaneously decrease required energy to reach molten state than pure $\mathrm{Li}_{2} \mathrm{CO}_{3}$ electrolyte and doesn't contain $\mathrm{K}_{2} \mathrm{CO}_{3}$ that is speculated to be the most corrosive to nickel anode among $\mathrm{Li}-\mathrm{Na}-\mathrm{K}$ carbonates. ${ }^{34-36}$ Additionally, electrolysis in $\mathrm{Li}-\mathrm{Na}$ eutectic carbonates of $50: 50 \mathrm{wt} \%$ at $600{ }^{\circ} \mathrm{C}$ provides a cost effective pathway to achieve the transition from $\mathrm{CO}_{2}$ into carbon sphere subsequent to electrolysis for $1 \mathrm{~h}$ at $100 \mathrm{~mA} \mathrm{~cm}^{-2}$ with a coulomb efficiency of $\sim 85.4 \%$. Recently it has been introduced that ${ }^{21}$ electrolysis in $\mathrm{Li}-\mathrm{Na}$ carbonates electrolyte mixed by $50: 50 \mathrm{wt} \%$ at $750{ }^{\circ} \mathrm{C}, 200 \mathrm{~mA} \mathrm{~cm}{ }^{-2}$, generates a carbon product comprising over $85 \%$ carbon nanotube (Fig. 4e and $\mathrm{f}$ ), strongly incentivizing to degrade atmospheric $\mathrm{CO}_{2}$ level by introduced molten salts electrolysis. Carbon nanotube, seamless cylinders of one or more layers of graphene, has shown promising performance for various applications involving supercapacitors, actuators, lightweight electromagnetic shields, etc., due to its outstanding mechanical strength and electrical or thermal conductivities. ${ }^{37,38}$ Gas phase $\mathrm{CO}_{2}$ dissolves and this has been isotopically traced as the source of the carbon nanotubes formed by molten carbonate electrolysis. ${ }^{39}$ As summarized by Licht group, ${ }^{20,21}$ formation factors of carbon nanotube at above mentioned electrolyte could be concluded as: (1) the utilization of a $\mathrm{Zn}$-coated steel cathode ( $\mathrm{Zn}$ can effectively lower the needed energy during carbon formation at the starting stage), (2) a constrained nickel concentration in electrolyte from anodic oxidation. An initial low current density subsequent by a higher current density is shown to be necessary for the controlled growth of carbon nanotube in pure $\mathrm{Li}_{2} \mathrm{CO}_{3}$ and $\mathrm{Li}-\mathrm{Na}$ carbonates mixed by $\sim 90: 10 \mathrm{wt} \%$, but in electrolyte of $\mathrm{Li}-\mathrm{Na}$ carbonates mixed by $50: 50 \mathrm{wt} \%$, carbon nanotube growth can proceed without the step of gradual increase in applied current density. As further presented by the Licht group, straight, rather than tangled, carbon nanotube is formed in pure $\mathrm{Li}_{2} \mathrm{CO}_{3}$ electrolyte, while electrolysis in $\mathrm{Li}-\mathrm{Na}$ mixed carbonates tends to generate tangled carbon nanotube, ascribed to $\mathrm{sp}^{3}$ defects in the $\mathrm{sp}^{2}$ graphene layered structures. ${ }^{40}$ Furthermore, wall thickness of the synthesized carbon nanotube can also be controlled by regulating electrolyte composition: electrolysis in $\mathrm{Li}_{2} \mathrm{CO}_{3}$ mixed with sufficient $\mathrm{CaCO}_{3}$ prefers synthesizing thin-walled carbon nanotubes, while in pure $\mathrm{Li}_{2} \mathrm{CO}_{3}$ electrolyte, thicker carbon nanotube becomes the preferable synthetic product. ${ }^{\mathbf{4 0}}$ According to recent reports, ${ }^{\mathbf{4 1}}$ optimized storage capacities of the as-prepared, low-cost, $\mathrm{CO}_{2}$ derived carbon nanotube are measured over $370 \mathrm{~mA} \mathrm{~h} \mathrm{~g}^{-1}$ and $130 \mathrm{~mA} \mathrm{~h} \mathrm{~g}{ }^{-1}$ owing to synthetic control of $\mathrm{sp}^{3}$ content in the synthetic nanostructures, with no capacity fade under durability tests up to 200 and 600 cycles in Li-ion and $\mathrm{Na}$-ion batteries, respectively. These findings based on experiments strongly demonstrate the fact that ambient $\mathrm{CO}_{2}$ could act as raw feedstock in industrial production, and this transformation provides a path to eliminate carbon dioxide emissions from power or cement plants. ${ }^{39,42,43}$

XRD characterization (Fig. 5) was performed to reveal the crystal characteristics of the carbon product prepared at different molten salts composition, wherein no obvious sharp

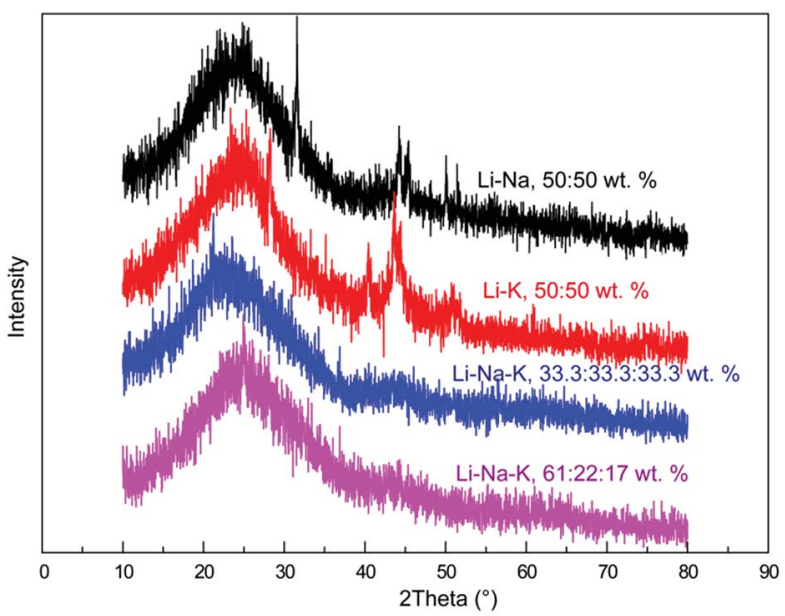

Fig. 5 XRD diffraction patterns of the carbon material electrodeposited at diverse carbonates, $100 \mathrm{~mA} \mathrm{~cm}^{-2}, 600^{\circ} \mathrm{C}$.

diffraction peak of carbon appears, signifying that the obtained carbon product in this work is mostly amorphous. This crystal characteristic could be ascribed to the conjecture that the crystal defects formed by disordering and irregular hexagonal annular plane make it challenging to pinpoint the location of the characteristic peaks of carbon. Whereas, an earlier application of a $\mathrm{Zn}$ coated (galvanized) steel cathode and a nickel anode to a pure $\mathrm{Li}_{2} \mathrm{CO}_{3}$ electrolyte seems to be an excellent work for generating carbon nanofiber possessing a much better crystal. $^{20}$ We should note that the presence of some microstructures with preferable crystal form in above carbon samples can't be denied, and maybe it's the existence of massive amorphous carbon that results in an overall crystal defect.

\subsection{Energy consumption}

Cell-voltage plots in Fig. 6 are recorded during electrolysis reaction at diverse electrolyte composition and current densities with electrochemical workstation. Obviously, cell-voltage values

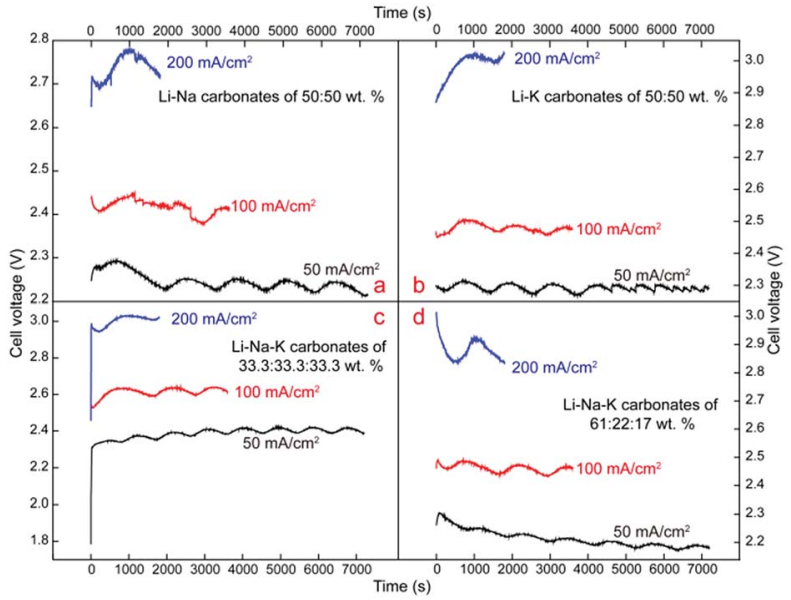

Fig. 6 Cell-voltage plots during $600{ }^{\circ} \mathrm{C}$ electrolysis in different electrolytes. 
increase at elevated current densities, which is consistent with the anticipated increase in overpotential with increasing current density. In terms of cell-voltage of $50 \mathrm{~mA} \mathrm{~cm}{ }^{-2}, \mathrm{Li}-\mathrm{Na}(50: 50$ wt\%), Li-K (50: 50 wt\%) and Li-Na-K (61: $22: 17$ wt\%) steady at $2.2-2.3 \mathrm{~V}$, while $\mathrm{Li}-\mathrm{Na}-\mathrm{K}(33.3: 33.3: 33.3 \mathrm{wt} \%)$ has a minor increase, floating at 2.3-2.4 V. Similarly, cell voltage of $\mathrm{Li}-\mathrm{Na}$ (50: $50 \mathrm{wt} \%$ ), Li-K (50:50 wt\%) and Li-Na-K (61:22:17 wt\%) at $100 \mathrm{~mA} \mathrm{~cm}^{-2}$ is in the range of $2.4-2.5 \mathrm{~V}$, and an amplification of $0.1-0.2 \mathrm{~V}$ is also observed at $\mathrm{Li}-\mathrm{Na}-\mathrm{K}(33.3: 33.3: 33.3 \mathrm{wt} \%)$. As the applied current density increases to $200 \mathrm{~mA} \mathrm{~cm}{ }^{-2}$, compared to the lowest cell-voltage at $\mathrm{Li}-\mathrm{Na}$ (50:50 wt\%), within the range of $2.7-2.8 \mathrm{~V}, \mathrm{Li}-\mathrm{K}(50: 50 \mathrm{wt} \%$ ) and $\mathrm{Li}-\mathrm{Na}-\mathrm{K}$ (61: $22: 17$ wt\%) have an obvious and significant increase of $0.2-0.3 \mathrm{~V}$, steadying at $2.8-3.0 \mathrm{~V}$, while $\mathrm{Li}-\mathrm{Na}-\mathrm{K}(33.3: 33.3: 33.3$ wt $\%$ ) presents a stable cell-voltage of $\sim 3 \mathrm{~V}$. Though the minor fluctuations probably caused by the stability of electrolyte system, electrode corrosion, variations in electrolytic temperature etc., are found to occur at constant current density electrolysis, the overall trend is relatively stable, signifying that this system tends to provide a mild and stable site for $\mathrm{CO}_{2}$ capture and carbon deposition.

Coulomb efficiency under different electrolytic conditions is measured in term of the moles of carbon deposited at cathode and electricity consumed by electrolysis process (4F per mole of carbon). As shown in Fig. 7a, coulomb efficiency for carbongeneration ranges from $\sim 61.8 \%$ to $\sim 94.9 \%$, which is considered to be a very satisfying result. In $\mathrm{Li}-\mathrm{Na}(50: 50 \mathrm{wt} \%)$ and $\mathrm{Li}-$ Na-K (61: $22: 17$ wt\%), electrolysis at different current densities, the most ideal coulomb efficiency is obtained at $200 \mathrm{~mA}$ $\mathrm{cm}^{-2}$, while in $\mathrm{Li}-\mathrm{K}(50: 50 \mathrm{wt} \%)$ and $\mathrm{Li}-\mathrm{Na}-\mathrm{K}(33.3: 33.3: 33.3$ wt\%), optimum coulomb efficiency is gained at $100 \mathrm{~mA} \mathrm{~cm}{ }^{-2}$. As previously noted that solubility of nickel cation increases at sodium-containing and potassium-containing carbonates electrolyte, and predictably, pure $\mathrm{Na} / \mathrm{K}$ carbonate electrolyte could be exceeding corrosive to the nickel anode, prompting the electrolyte to turns from transparent to green. ${ }^{20}$ Thus, in electrolyte containing high concentrations of $\mathrm{Na}^{+}$and $\mathrm{K}^{+}$, a lower coulomb efficiency and a serious anode corrosion are often observed, such as in electrolyte of $\mathrm{Li}-\mathrm{Na}-\mathrm{K}$ ternary carbonates (33.3 : $33.3: 33.3 \mathrm{wt} \%$ ) at $200 \mathrm{~mA} \mathrm{~cm}^{-2}$. Compared with another ternary $\mathrm{Li}-\mathrm{Na}-\mathrm{K}$ system $(61: 22: 17 \mathrm{wt} \%)$ and binary carbonates electrolyte ( $\mathrm{Li}-\mathrm{Na}, \mathrm{Li}-\mathrm{K}, \quad 50: 50 \mathrm{wt} \%)$, a noticeable shrinkage in coulomb efficiency occurs in $\mathrm{Li}-\mathrm{Na}-\mathrm{K}$ system

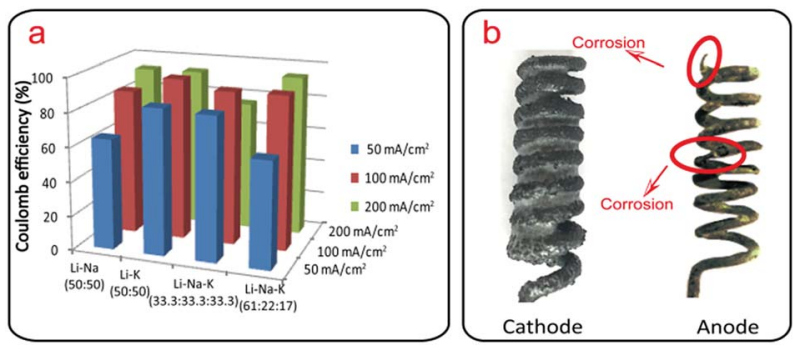

Fig. 7 (a) Coulomb efficiency at different electrolytic conditions; (b) images of electrodes after electrolysis in $\mathrm{Li}-\mathrm{Na}-\mathrm{K}$ carbonates (33.3 : $33.3: 33.3 \mathrm{wt} \%$ ) at $200 \mathrm{~mA} \mathrm{~cm}^{-2}$ for $0.5 \mathrm{~h}$.
(33.3 : $33.3: 33.3 \mathrm{wt} \%)$ at $200 \mathrm{~mA} \mathrm{~cm}^{-2}(<80 \%)$, and the discussed anode corrosion above can give answers to this phenomenon. Generally, an enlarged current density leads to a violent anode corrosion, however, in spite of the weak anodic corrosion at lower applied current density, the lowest coulomb efficiency is found at $50 \mathrm{~mA} \mathrm{~cm}{ }^{-2}$ in $\mathrm{Li}-\mathrm{Na}$ (50:50 wt\%), $\mathrm{Li}-\mathrm{K}$ (50:50 wt\%) and Li-Na-K (61:22:17 wt\%), which could be attributed to the primarily slower deposition rate. In contrast, at electrolyte of $\mathrm{Li}-\mathrm{Na}-\mathrm{K}$ (33.3 : 33.3 : $33.3 \mathrm{wt} \%$ ), anodic corrosion becomes first and foremost due to the elevated concentration of $\mathrm{Na}^{+}$and $\mathrm{K}^{+}$, leading to the lowest coulomb efficiency at $200 \mathrm{~mA}$ $\mathrm{cm}^{-2}$. Anode images after electrolysis at $\mathrm{Li}-\mathrm{Na}-\mathrm{K}$ ternary electrolyte $(33.3: 33.3: 33.3 \mathrm{wt} \%)$ at $200 \mathrm{~mA} \mathrm{~cm}{ }^{-2}$ for $0.5 \mathrm{~h}$ are depicted in Fig. 7b. In addition to a thick layer of frozen electrolyte adhering on the surface, a serious anode corrosion is also observed (red-marked parts are after removing attached frozen electrolyte), meaning the charge passed through the electrolyzer besides achieving the reduction of $\mathrm{CO}_{3}{ }^{2-}$ into carbon deposit, and simultaneously oxidizes $\mathrm{Ni}$ into $\mathrm{Ni}^{2+}$ (the electrolyte turns from transparent to green), resulting in the decrease of coulomb efficiency. This is consistent with the finding that the oxygen-generating anode effects promote significant carbon product formation at cathode. ${ }^{20}$ Note, that the anodic corrosion seems to be general but inhomogeneous presumably for the uneven anode polarization current. However, in an electrolyte containing higher concentrations of Li cation (61:22:17 wt\%), the Ni anode corrosion is not evident, further manifesting that the cation composition of the carbonate electrolyte determines the extent of nickel anode corrosion notably.

\section{Conclusions}

This paper for the first time presents a comparison among electrolysis in $\mathrm{Li}-\mathrm{Na}$ (50 : $50 \mathrm{wt} \%$ ), Li-K (50:50 wt\%), Li-Na-K (33.3 : $33.3: 33.3 \mathrm{wt} \%)$, and $\mathrm{Li}-\mathrm{Na}-\mathrm{K}(61: 22: 17 \mathrm{wt} \%)$, and highlights the effect of carbonates composition on cathodic carbon deposition (morphology and structure) as well as coulomb efficiency for carbon generation. Besides carbon flake with diverse thickness that is often observed in previous relevant publications, very interesting spherical aggregates that possess a potential to be used as elastomer filler are formed during electrolysis in Li-Na electrolyte mixed by $50: 50 \mathrm{wt} \%$ at $100 \mathrm{~mA} \mathrm{~cm}^{-2}$. Moreover, carbon nanotube, a valuable chemical, is obtained at cathode in the same electrolyte, but higher electrolytic temperature of $750{ }^{\circ} \mathrm{C}$. Another result concluded from this work is that molten carbonates composition could influence anode corrosion powerfully, and then recorded cell voltage and calculated coulomb efficiency (the most ideal efficiency approaching $94.9 \%$ in $\mathrm{Li}-\mathrm{K}$ electrolyte at $100 \mathrm{~mA} \mathrm{~cm} \mathrm{~cm}^{-2}$ ) are indirectly affected. Energy consumption is an urgent problem to be solved and a subsequent challenging task we face is how to combine renewable energy source with this electrochemical system, to pander to environmental sustainability. In sum, converting ambient $\mathrm{CO}_{2}$ into value-added carbonaceous materials via molten salts electrolysis technology is critical for sustainable development and deserves our further investigation. 


\section{Acknowledgements}

This work is supported by the National Natural Science Foundation of China (No. 21476046 and 21306022), Specialized Research Fund for the Doctoral Program of Higher Education of China (No. 20132322120002), China Postdoctoral Science Foundation (No. 2013M540269), Postdoctoral Science Foundation of Heilongjiang Province of China (No. LBH-TZ0417), Innovative Team of Science and Technology in Heilongjiang Higher Education Institutes (No. 2013TD004) and Northeast Petroleum University (No. SJQHB201602 and YJSCX2016-018 NEPU). We are grateful to Professor Stuart Licht (The George Washington University) for valuable contributions to the research.

\section{Notes and references}

1 K. E. Lonngren and E. Bai, Energy Policy, 2008, 36, 1567-1568.

2 P. Friedlingstein, R. M. Andrew, J. Rogelj, G. P. Peters, J. G. Canadell, R. Knutti, G. Luderer, M. R. Raupach, M. Schaeffer, D. P. van Vuuren and C. Le Quéré, Nat. Geosci., 2014, 7, 709-715.

3 D. Huisingh, Z. Zhang, J. C. Moore, Q. Qiao and Q. Li, J. Cleaner Prod., 2015, 103, 1-12.

4 Y. H. Cheng, Y. H. Chang and I. J. Lu, Appl. Energy, 2015, 157, 953-973.

5 G. T. Rochelle, Science, 2009, 325, 1652-1654.

6 T. Viktorija, S. Asbjørn and O. Espen, Energy Fuels, 2013, 27, 5373-5379.

7 S. Xiang, Y. He, Z. Zhang, H. Wu, W. Zhou, R. Krishna and B. Chen, Nat. Commun., 2012, 3, 954-962.

8 J. Byun, S.-H. Je, H. A. Patel, A. Coskun and C. T. Yavuz, J. Mater. Chem. A, 2014, 2, 12507-12512.

9 A. Wahby, J. M. Ramos-Ferńandez, M. Martínez-Escandell, A. Sepúlveda-Escribano, J. Silvestre-Albero and F. RodríguezReinoso, ChemSusChem, 2010, 3, 974-981.

10 B. Ashourirad, P. Arab, T. Islamoglu, K. A. Cychosz, M. Thommes and H. M. El-Kaderi, J. Mater. Chem. A, 2016, 4, 14693-14702.

11 Z. Zhang and D. Huisingh, J. Cleaner Prod., 2016, 30, 1-10.

12 X. Gao, B. Yu, Z. Yang, Y. Zhao, H. Zhang, L. Hao, B. Han and Z. Liu, ACS Catal., 2015, 5, 6648-6652.

13 G. P. S. Lau, M. R. Schreier, D. Vasilyev, R. Scopelliti, M. Grätzel and P. J. Dyson, J. Am. Chem. Soc., 2016, 138, 7820-7823.

14 H. V. Ijije, R. C. Lawrence and G. Z. Chen, $R S C A d v .$, 2014, 4, 35808-35817.

15 Y. Kanai, K. Fukunaga, K. Terasaka and S. Fujioka, Chem. Eng. Sci., 2013, 100, 153-159.

16 Z. Shi, W. Deng, X. Song, X. Hu, B. Gao and Z. Wang, J. Chem. Eng. Data, 2016, 61, 3020-3026.

17 W. Zhu, R. Michalsky, Ö. Metin, H. Lv, S. Guo, C. J. Wright, X. Sun, A. A. Peterson and S. Sun, J. Am. Chem. Soc., 2013, 135, 16833-16836.

18 H. Yin, X. Mao, D. Tang, W. Xiao, L. Xing, H. Zhu, D. Wang and D. R. Sadoway, Energy Environ. Sci., 2013, 6, 1538-1545.
19 B. Deng, Z. Chen, M. Gao, Y. Song, K. Zheng, J. Tang, W. Xiao, X. Mao and D. Wang, Faraday Discuss., 2016, 190, 241-258.

20 J. Ren, F. F. Li, J. Lau, L. González-Urbina and S. Licht, Nano Lett., 2015, 15, 6142-6148.

21 H. Wu, Z. Li, D. Ji, Y. Liu, L. Li, D. Yuan, Z. Zhang, J. Ren, M. Lefler, B. Wang and S. Licht, Carbon, 2016, 106, 208-217.

22 J. Ren, J. Lau, M. Lefler and S. Licht, J. Phys. Chem. C, 2015, 119, 23342-23349.

23 D. Tang, H. Yin, X. Mao, W. Xiao and D. H. Wang, Electrochim. Acta, 2013, 114, 567-573.

24 H. Wu, D. Ji, L. Li, D. Yuan, Y. Zhu, B. Wang, Z. Zhang and S. Licht, Advanced Materials Technologies, 2016, 1, 1-10.

25 L. Mao, J. Qiu and L. Xing, Mater. Lett., 2008, 62, 581-583.

26 L. Xu, W. Zhang, Q. Yang, Y. Ding, W. Yu and Y. Qian, Carbon, 2005, 43, 1090-1092.

27 L. Tosheva, J. Parmentier, V. Valtchev, C. Vix-Guterl and J. Patarin, Carbon, 2005, 43, 2474-2480.

28 J. Martin-Gil, F. J. Martin-Gil, E. Moran, M. Miki-Yoshida, L. Martinez and M. José-Yacaman, Acta Metall. Mater., 1995, 43, 1243-1247.

29 Q. Wang, F. Cao, Q. Chen and C. Chen, Mater. Lett., 2005, 59, 3738-3741.

30 W. Li, D. Chen, Z. Li, Y. Shi, Y. Wan, G. Wang, Z. Jiang and D. Zhao, Carbon, 2007, 45, 1757-1763.

31 B. Friedel and S. Greulich-Weber, Small, 2006, 2, 859-863.

32 Q. Lin, M. Zheng, T. Qin, R. Guo and P. Tian, J. Anal. Appl. Pyrolysis, 2010, 89, 112-116.

33 A. A. Deshmukh, S. D. Mhlanga and N. J. Coville, Mater. Sci. Eng., $R, 2010$, 70, 1-28.

34 S. Mahammadunnisa, E. L. Reddy, D. Ray, C. Subrahmanyam and J. C. Whitehead, Int. J. Greenhouse Gas Control, 2013, 16, 361-363.

35 I. A. Novoselova, N. F. Oliinyk, S. V. Volkov, A. A. Konchits, I. B. Yanchuk, V. S. Yefanov, S. P. Kolesnik and M. V. Karpets, Phys. E, 2008, 40, 2231-2237.

36 (a) F. F. Li, S. Liu, B. Cui, J. Lau, J. Stuart, B. Wang and S. Licht, Adv. Energy Mater., 2015, 5, 1-7; (b) S. Licht, Stabilization of STEP electrolytes, 2012, accessed Jan 2017, http://arxiv.org/pdf/1209.3512.pdf.

37 S. Iijima, Nature, 1991, 354, 56-58.

38 M. F. L. D. Volder, S. H. Tawfick, R. H. Baughman and A. J. Hart, Science, 2013, 339, 535-539.

39 J. Ren and S. Licht, Sci. Rep., 2016, 6, 27760-27760.

40 S. Licht, M. Lefler, J. Ren and J. Vicini, arXiv preprint arXiv:1607.02220, 2016, in press.

41 S. Licht, A. Douglas, J. Ren, R. Carter, M. Lefler and C. L. Pint, ACS Cent. Sci., 2016, 2, 162-168.

42 S. Licht, Co-Production of Cement and Carbon Nanotubes with a Carbon Negative Footprint, 2016, accessed Jan 2017, https:// arxiv.org/pdf/1608.00946v1.pdf.

43 J. Lau, G. Dey and G. S. Licht, Energy Convers. Manage., 2016, 122, 400-410. 